\title{
Mediação Pedagógica, Afetiva e Operacional, Práticas de uma Tutoria na Educação a Distância
}

\section{Pedagogical, Affective and Operational Mediation, Practices of a Distance Education Tutoring}

\author{
Dayane Verginia Batista Bessa*a; Fátima Aparecida da Silva Dias; Samira Fayes Kfouri da Silva ${ }^{\mathrm{a}}$; Maria Elisabette \\ Brisola Brito Prado
}

\author{
aUnopar, Programa de Pós-Graduação Stricto Sensu em Metodologias para o Ensino e suas Tecnologias. PR, Brasil. \\ bUniversidade Anhanguera de São Paulo, Programa de Pós-Graduação Stricto Sensu em Educação Matemática. SP, Brasil. \\ *E-mail: dayanebbessa@gmail.com \\ Recebido em: 11/06/19; Aceito em: 23/08/19
}

\begin{abstract}
Resumo
Este artigo tem por propósito apresentar o recorte da pesquisa de mestrado que analisou a compreensão do tutor, que atua no Ensino Superior, acerca da tríade da mediação. O referencial teórico relativo à Educação a Distância se pautou nos documentos oficiais, que regulamentam a oferta desta modalidade de ensino entre Leis e Decretos, além de pesquisadores como Moore. Quanto ao conceito de mediação, apoiou-se nas pesquisas realizadas por Masetto, Almeida, Moran, Freire e também no exposto nos referenciais de qualidade para a Educação a distância. A metodologia utilizada nesta pesquisa foi do tipo exploratória, de cunho qualitativo. Os procedimentos metodológicos foram estruturados na elaboração do instrumento questionário, aplicação e análise dos dados. A análise dos dados foi realizada em duas etapas: i. documental; ii.questionário aplicado aos participantes da pesquisa e relatos dos mesmos. Neste artigo se discute parte da análise da segunda etapa, que descreve a atuação dos tutores em relação à mediação pedagógica, afetiva e operacional, tríade de mediação objeto de estudo dos tutores pesquisados. Os resultados evidenciaram que os tutores compreendem a importância da mediação em suas ações junto aos alunos, porém muitos ainda não compreendem a tríade de mediação como um processo contínuo e que os programas de formação continuada oferecidos pela instituição contribuem diretamente para o enriquecimento profissional de seus tutores.
\end{abstract}

Palavras-chave: Mediação. Educação a Distância. Ensino Superior.

\begin{abstract}
This article aims to present the outline of the master's research that analyzed the understanding of the tutor working in higher education about the mediation triad. The theoretical reference related to Distance Education, was based on the official documents that regulate the offer of this teaching modality between Laws and Decrees, besides researchers like Moore. As for the mediation concept, it was based on research by Masetto, Almeida, Moran, Freire and also on the quality references for distance education. The methodology used in this research was exploratory, qualitative in nature. The methodological procedures were structured in the elaboration of the questionnaire instrument, application and data analysis. Data analysis was performed in two steps: i. Documentary; Questionnaire applied to the research participants and their reports. In this article part of the analysis of the second stage is discussed that describes the tutors' role in relation to pedagogical, affective and operational mediation, triad of mediation object of study of the researched tutors. The results showed that tutors understand the mediation importance in their actions with students, but many do not understand the mediation triad yet as a continuous process and that the continuing education programs offered by the institution contribute directly to the professional enrichment of the students'tutors.
\end{abstract}

Keywords: Mediation. Distance Education. Higher Education.

\section{Introdução}

Composto por coordenadores de diversos cursos da instituição, o grupo de trabalho denominado Tutoria Disruptiva, de uma Universidade da Cidade de Londrina, Estado do Paraná, realizaram estudos acerca de novas possibilidades para a tutoria já implantada na Universidade. A partir das discussões realizadas no grupo de trabalho, um novo modelo de tutoria foi proposto, visando melhorias na atuação dos tutores da Universidade.

Neste modelo, tutores de diferentes áreas de conhecimento foram selecionados e passaram a fazer parte do projeto piloto de tutoria, em que trabalhavam 30 horas semanais internas na Universidade. Ressalta-se que o modelo de tutoria que antecede a proposta atual tinha um caráter bastante diferente, visto que os tutores trabalhavam 24 horas semanais, ficando um período de quatro horas na Universidade a cada quinzena e as demais horas eram cumpridas remotamente.

Os tutores desse novo modelo participaram de classes de formação sobre o modelo tríplice de mediação, composto pelas mediações do tipo pedagógica, afetiva e operacional, além de receberem o apoio diário dos docentes e da coordenação. Eles vivenciaram um processo de formação continuada, participando de cursos disponibilizados na plataforma online e presencial, tendo sido acompanhados por uma equipe pedagógica, professores, coordenadores, além de docentes pesquisadores de Universidades parceiras.

Isso posto, este artigo tem por objetivo apresentar um recorte de uma dissertação de mestrado, abordando parte de um questionário respondido pelos tutores na pesquisa realizada, a fim de identificar o entendimento de um grupo 
de tutores online acerca da tríade formada pelas mediações pedagógica, afetiva e operacional e verificar a compreensão do tutor acerca da mediação.

\section{Material e Métodos}

A Universidade participante desta pesquisa é reconhecida como uma das primeiras a ofertar Educação Superior a Distância no Brasil. Com o credenciamento para atuar nessa modalidade recebido via Ministério da Educação - MEC em dezembro de 2002, a instituição deu início às atividades da Educação a Distância - EaD no ano de 2003, tendo como a primeira graduação o curso Normal Superior.

Desde a implantação e atuação na Educação a Distância da Universidade pesquisada, muitos foram os avanços e mudanças que ocorreram. Ao longo desses anos de atuação, a instituição se consolidou como a maior instituição nessa modalidade de educação do país, com mais de 300 mil alunos e com a oferta de mais de 30 cursos superiores entre licenciaturas, bacharelados e superiores em tecnologia.

Diante desses avanços, a tutoria a distância também passou por mudanças que visaram o acompanhamento do progresso da $\mathrm{EaD}$ na instituição, assim como no mundo. $\mathrm{O}$ modelo de atuação dos tutores, que perdurou por mais tempo na instituição foi o regime de 24 horas semanais. O tutor estava presente na instituição quinzenalmente, sendo as demais horas cumpridas a distância, ou seja, fora da instituição. Nesse modelo, os tutores tinham contato presencial com os docentes e coordenação de cursos apenas a cada 15 dias, nos demais dias, o contato ocorria via e-mail e/ou Ambiente Virtual de Aprendizagem - AVA.

Com o passar dos anos, do crescimento do número de alunos e de propostas de novas metodologias, houve um repensar referente à prática dos tutores, principalmente no que se refere ao modelo de atuação, à formação continuada e ao atendimento aos alunos.

Para o exercício do repensar as práticas exercidas na instituição, a Universidade dispunha de projetos internos, que visavam melhoria dos processos já realizados ou, até mesmo, a implantação de novos. Para tanto, foram criados grupos de trabalho envolvendo os diferentes atores da Educação a Distância de acordo com o objetivo estabelecido para cada grupo, desses grupos participavam tutores, professores, coordenações de curso e demais envolvidos no processo.

Entre os grupos se destaca o Tutoria Disruptiva, que tinha por objetivo a reestruturação do modelo de tutoria exercido na instituição. Esse grupo era composto por coordenadores de curso e, ao longo das discussões, professores e tutores foram convidados para relatarem suas experiências de atuação no AVA, suas relações entre os pares e com os alunos, para que fosse possível um repensar sobre a prática de tutoria exercida na instituição.

A participação dos tutores no grupo de trabalho foi fundamental, pois tiveram a oportunidade de apresentar, ao grupo de trabalho, suas considerações quanto à própria atuação e, também, sugestões de melhorias visando o progresso da mediação junto aos alunos. A atuação dos professores permitiu ao grupo de trabalho identificar a interação entre tutores e alunos. A participação das coordenações de curso possibilitou a verificação da mediação dos tutores junto aos alunos e professores, além das demandas operacionais no que se referia às solicitações dos alunos e à execução das demandas pedagógicas por parte dos tutores e professores ao longo do semestre.

Com o apoio de tutores, que atuaram como participantes do grupo de trabalho, a análise do AVA de alguns tutores e com base nas discussões realizadas, o grupo identificou a necessidade de desenvolver três tipos de mediação, denominadas: pedagógica, afetiva e operacional.

Muitas das interações entre tutores e alunos estavam relacionadas aos conteúdos trabalhados nas teleaulas e nas atividades propostas pelos docentes, tendo sido analisadas também mensagens de acolhida e de envolvimento dos alunos no curso, ao longo do semestre, e mensagens sobre questões administrativas e operacionais (erro no sistema, data de provas e trabalhos, atestado médico, não postagem de atividades e outras).

Após inúmeras discussões, hipóteses foram traçadas, a fim de alavancar a atuação dos tutores nos cursos a distância da Universidade pesquisada. Assim sendo, estabeleceu-se a criação de um projeto piloto de tutoria em que os tutores passaram a trabalhar 30 horas semanais, internalizados na instituição, extinguindo, assim, a carga horária home office, o que permitiu a eles um maior convívio com o corpo docente e coordenação de curso.

Os tutores do projeto piloto passavam, ainda, por formações referentes à mediação e a sua importância na tutoria. Além disso, semanalmente, os docentes apresentavam um breve resumo da aula a ser ministrada para que os tutores pudessem tirar suas dúvidas quanto ao conteúdo e, também, detalhavam as questões das provas e trabalhos.

Tendo como proposta o acompanhamento do trabalho do tutor a distância no que diz respeito à mediação no AVA, realizou-se uma pesquisa do tipo exploratória, de cunho qualitativo, por possuir a característica de trabalhar com crenças, representações, valores, hábitos, atitudes e opiniões e por ser um tipo de investigação interpretativo-formativa, que busca a compreensão do tema pesquisado, favorecendo o processo de descobrimento, por meio de análise, síntese de ideias e conceitos, com envolvimento de aspectos emocionais e contextuais.

De acordo com Minayo (1994, p.10):

As pesquisas qualitativas são entendidas como aquelas capazes de incorporar a questão do significado e da intencionalidade como inerentes aos atos, as relações e as estruturas sociais, sendo essas últimas tomadas tanto no seu advento, quanto na sua transformação, como construções humanas significativas.

A autora destaca que a abordagem qualitativa não pode 
pretender o alcance da verdade, como o que é certo ou errado, mas se preocupar primeiramente com a compreensão da lógica, que permeia a prática realizada na realidade.

Desta pesquisa, participaram 23 tutores de diferentes áreas de formação da Educação Superior a distância em licenciatura, bacharelado e tecnólogo da Universidade. Os participantes faziam parte do projeto piloto Tutoria Disruptiva e trabalhavam em regime de 30 horas semanais, cumpridas na instituição.

Vale ressaltar que a seleção dos tutores ocorreu mediante as discussões realizadas no grupo de trabalho, que estabeleceu a criação de um projeto piloto de tutoria, composto por parte dos tutores online ativos na instituição, desse modo os tutores participantes desta pesquisa compuseram apenas uma parte dos tutores online da Universidade.

\subsection{O caminho metodológico}

Tratando-se de um recorte de uma pesquisa de mestrado, este artigo se pauta na etapa da pesquisa na qual foi estruturado um instrumento de coleta de dados com base na tríade de mediação (pedagógica, afetiva e operacional), para identificar qual delas mais se evidenciava na atuação do tutor no AVA - fórum de discussão, sistema de mensagens e sala do tutor. Assinala-se que os tutores pesquisados passaram por um processo de formação continuada, a fim de melhor compreender o conceito de mediação e a tríade proposta nesta pesquisa.

O questionário foi composto por 11 questões, abertas e fechadas, e foi aplicado aos tutores participantes da formação com a proposta de constatar a compreensão deles sobre as mediações pedagógica, afetiva e operacional ao longo do processo.

Para seleção dos tutores, o critério adotado foi o de que deveriam fazer parte do piloto do projeto Tutoria Disruptiva e estarem participando do curso de formação Letramento Estatístico, que teve como objetivo proporcionar aos tutores a vivência no ambiente virtual de aprendizagem, enquanto alunos, possibilitando aos tutores momentos de interação acerca da mediação pedagógica, afetiva e operacional. A aplicação do questionário foi realizada pelo pesquisador em uma sala da Universidade na qual se encontravam os tutores participantes. Antes da apresentação do questionário, os objetivos desta pesquisa foram apresentados aos participantes, que puderam tirar suas dúvidas. Em seguida, todos responderam ao questionário com base em suas experiências na tutoria da Universidade.

Após responderem o questionário, para o tratamento dos dados, usam-se recursos computacionais, como planilhas e gráficos e o aplicativo de criação de nuvem de palavras Word Cloud. As planilhas e os gráficos permitiram analisar as respostas das questões objetivas e o sistema de nuvem, as respostas discursivas.

Para melhor compreensão dos tipos de mediação que compõem a tríade, define-se a seguir cada ponto deste tripé que compõe a mediação realizada pelos tutores de Educação a Distância da Universidade. Inicia-se pela mediação Pedagógica com a contribuição de Masetto (2009, p.145) que define:

Por mediação pedagógica entendemos a atitude, o comportamento do professor que se coloca como um facilitador, incentivador ou motivador da aprendizagem, que se apresenta com a disposição de ser uma ponte entre o aprendiz e sua aprendizagem - não uma ponte estática, mas uma ponte "rolante", que ativamente colabora para que o aprendiz chegue aos seus objetivos. É a forma de se apresentar e tratar um conteúdo ou tema que ajuda o aprendiz a coletar informações, relacioná-las, organizá-las, manipulálas, discuti-las e debatê-las com seus colegas, com o professor e com outras pessoas (interaprendizagem), até chegar a produzir um conhecimento que seja significativo para ele, conhecimento que se incorpore ao seu mundo intelectual e vivencial, e que o ajude a compreender sua realidade humana e social, e mesmo a interferir nela.

Deste modo, a mediação Pedagógica realizada pelos tutores possui grande importância no processo de ensino e aprendizagem, portanto, é relevante que o tutor compreenda que é necessária uma organização das situações de intervenções pedagógicas direcionadas para promoção da aprendizagem, que ultrapasse a simples reprodução.

A mediação afetiva está presente na mediação realizada pelo tutor, Almeida (1999, p.107) corrobora ao dizer que "as relações afetivas se evidenciam, pois, a transmissão do conhecimento implica, necessariamente, uma interação entre pessoas. Portanto, na relação professor-aluno, uma relação de pessoa para pessoa, o afeto está presente". Ainda, compreendese que a imagem, a palavra e a música se integram dentro de um contexto comunicacional afetivo, de forte impacto emocional, que facilita e predispõe a aceitar mais facilmente as mensagens (MORAN, 2000).

Sobre a mediação afetiva, Silva (2009, p.97) assinala que:

$\mathrm{Na}$ comunicação entre professores e alunos, fundamentada no uso de TIC, deve-se considerar uma base conceitual que sustente o processo educacional que privilegie o diálogo motivador, garantindo a interatividade e propiciando o desenvolvimento da autonomia no processo de ensino e aprendizagem, porque é no diálogo que se pode observar a dinâmica do processo de interação das vozes sociais.

Moore (2013, p.191) corrobora com a mediação afetiva dizendo:

A criação de um ambiente que enfatize a importância do indivíduo e que gere uma sensação de relacionamento com o grupo. Isso pode ser realizado, por exemplo, usando os nomes dos alunos, mostrando fotografias dos participantes, perguntando sobre experiências pessoais e pedindo opiniões.

Já a mediação operacional está ligada aos assuntos administrativos da instituição, disponibilização dos materiais, dúvidas quanto ao acesso dos materiais, boletos, matrículas, agendamento de provas, atestados, assuntos que envolvem a operação da instituição. No que se refere às questões administrativas, os tutores repassam ao setor responsável para retorno aos alunos, conforme previsto nos referenciais de 
qualidade para Educação Superior a distância:

No que tange à dimensão administrativa, a equipe deve atuar em funções de secretaria acadêmica, no registro e acompanhamento de procedimentos de matrícula, avaliação e certificação dos estudantes, envolvendo o cumprimento de prazos e exigências legais em todas as instâncias acadêmicas; bem como no apoio ao corpo docente e de tutores nas atividades presenciais e a distância, distribuição e recebimento de material didático, atendimento a estudantes usuários de laboratórios e bibliotecas, entre outros (BRASIL, 2007, p. 23).

Moore (2013, p.182) corrobora também com o entendimento da mediação operacional ao dizer que:O instrutor $^{1}$ também precisa ser capaz de reconhecer os tipos de problemas com que lidam os serviços de apoio ao aluno, de modo que os enfrente antes que o aluno os reconheça ou esteja pronto para articulá-los. Por exemplo, um aluno que sempre entrega uma tarefa no último minuto pode estar apresentando dificuldade para gerenciar o tempo ou pode estar excessivamente ansioso a respeito do desempenho, o que um instrutor sensível perceberá e tentará resolver.

O processo de mediação realizado pelos tutores envolve aspectos que vão além dos conteúdos trabalhados nas teleaulas, portanto, cabe aos tutores um envolvimento plural nos processos da instituição e, também, no acolhimento dos alunos, para que o tripé da mediação pedagógica afetiva e operacional se efetive no dia a dia de trabalho.

\section{Resultados e Discussão}

Como exposto anteriormente, este artigo é um recorte de uma pesquisa de mestrado, portanto apresenta-se aqui os resultados da questão que tratava sobre a realização da tríade da mediação no dia a dia da tutoria. Ressalta-se que o questionário foi composto por doze questões e aborda-se aqui apenas uma questão.

Qual a mediação mais realizada em seu dia a dia no contato com os alunos no ambiente virtual de aprendizagem? Justifique sua resposta. O gráfico da Figura 1 representa a porcentagem de cada resposta.

Figura 1 - Quanto à mediação realizada

Com base na tríade da mediação, qual mediação mais realiza?

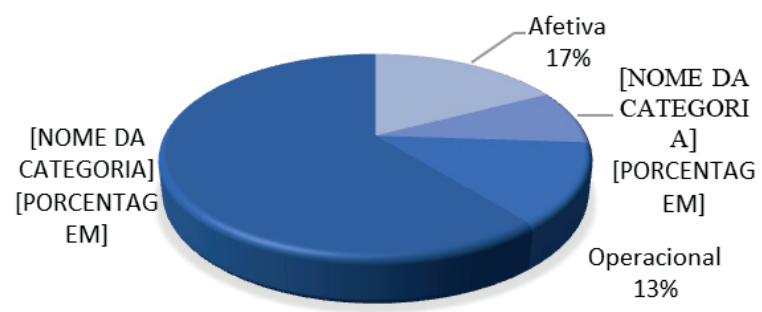

Fonte: Dados da pesquisa.

A partir do gráfico da Figura 1 é possível observar que a mediação pedagógica soma $61 \%$ das respostas, ou seja, possuía maior evidencia na atuação dos tutores de Educação a Distância envolvidos nesta pesquisa, tal evidência pode estar relacionada aos conteúdos trabalhados, que exigem dos tutores um maior acompanhamento junto aos alunos, Prado (2003, p.58) corrobora ao dizer que "na abordagem do estar junto virtual, se concretiza pelas constantes recriações de estratégias durante a realização de um curso, a partir da interrelação dos materiais, atividades e interações."

O Quadro 1 retrata a fala dos tutores justificando o motivo da escolha da mediação pedagógica quanto a mais exercida no dia a dia de trabalho. Se faz importante salientar, que embora tenham escolhido a mediação pedagógica, como a realizada com maior frequência, alguns tutores em suas justificativas relacionam a tríade de mediação pedagógica, afetiva e operacional em suas justificativas, por entenderem que a tríade se relaciona ao realizarem a mediação.

Quadro 1 - Justificativa dos tutores que alegaram realizar com maior frequência a mediação Pedagógica

\begin{tabular}{|c|c|}
\hline Tutor & Resposta \\
\hline $\mathbf{T 1}$ & $\begin{array}{l}\text { Estou atualmente com o último semestre, dessa forma } \\
\text { as interações operacionais são quase nulas. E acredito } \\
\text { que a afetiva caminhe junto com a pedagógica. }\end{array}$ \\
\hline T3 & $\begin{array}{l}\text { Estou num semestre que apresenta um portfólio com } \\
\text { um grau de dificuldade muito grande, dessa forma } \\
\text { os alunos tem enviado inúmeras dúvidas quanto a } \\
\text { realização do mesmo por mensagens e Sala do Tutor. }\end{array}$ \\
\hline T4 & $\begin{array}{l}\text { A frequência maior é a pedagógica. Os alunos ainda } \\
\text { ficam muito inseguros e com muitas dúvidas em } \\
\text { relação às orientações dos trabalhos. Com orientações } \\
\text { mais simples e diretas através da sala do tutor e } \\
\text { sistema de mensagem essas dúvidas são rapidamente } \\
\text { sanadas. }\end{array}$ \\
\hline T5 & Dúvidas sobre conteúdo \\
\hline T6 & $\begin{array}{l}\text { A demandada maior no momento é a pedagógica, } \\
\text { pois as orientações são referentes aos conteúdos que } \\
\text { estão vinculadas as disciplinas do curso de pedagogia. } \\
\text { Sendo assim, esta mediação ajuda esclarecer as } \\
\text { dúvidas referentes as atividades solicitadas. }\end{array}$ \\
\hline T8 & $\begin{array}{l}\text { Neste período letivo a grande concentração de dúvidas } \\
\text { é convergida para o portfólio, por este motivo grande } \\
\text { parte da mediação é pedagógica. }\end{array}$ \\
\hline T10 & $\begin{array}{l}\text { Espero estar desempenhando o papel de articulador e } \\
\text { integrador dos processos educativos, o qual possibilita } \\
\text { uma atualização do aprofundamento da disciplina } \\
\text { ajudando assim na complementação e ampliação } \\
\text { de conhecimentos para os alunos com base nesta } \\
\text { mediação, também levar as discussões e reflexões } \\
\text { sobre a prática pedagógica, através de um referencial } \\
\text { teórico-metodológico fundamentado na proposta } \\
\text { ofertada. }\end{array}$ \\
\hline T13 & $\begin{array}{l}\text { Na tríade o correto seria podermos aliar todas as } 3 \\
\text { bases, porém com a quantidade de alunos e demais } \\
\text { atribuições usamos mais a questão pedagógica e a } \\
\text { operacional, para termos uma mediação ao menos } \\
\text { compensadora. }\end{array}$ \\
\hline T14 & $\begin{array}{l}\text { A maior demanda que vem dos alunos se refere } \\
\text { a dúvidas pedagógicas de como seguir com suas } \\
\text { atividades recorrentes. Portanto a maior parte do } \\
\text { tempo se refere a estas questões. }\end{array}$ \\
\hline T15 & São as maiores dúvidas dos alunos \\
\hline
\end{tabular}




\begin{tabular}{|l|l|}
\hline T16 & $\begin{array}{l}\text { Para os alunos do sétimo semestre, não é comum } \\
\text { a evasão do curso, portanto, não é frequente as } \\
\text { mediações afetivas, somente é realizada para } \\
\text { aproximação e motivação. Nesta fase, a maioria dos } \\
\text { alunos, já tem fortes conhecimento sobre questões } \\
\text { operacionais, descartando assim, grande parte de } \\
\text { instruções, ficando somente a mediação operacional } \\
\text { para alguns casos específicos, como erros no sistema, } \\
\text { dúvidas de provas de segunda chamada entre outros. } \\
\text { Já a mediação pedagógica é intensa, as dúvidas são } \\
\text { frequentes e em todas as disciplinas do semestre. }\end{array}$ \\
\hline T19 & $\begin{array}{l}\text { Atendimento ao aluno esclarecendo dúvidas, em } \\
\text { relação ao conteúdo e orientando na realização das } \\
\text { atividades. }\end{array}$ \\
\hline T21 & $\begin{array}{l}\text { O Tutor tem um papel como orientador, como } \\
\text { mediador do processo de aprendizagem e facilitador } \\
\text { da aprendizagem colaborativa em rede. }\end{array}$ \\
\hline T22 & $\begin{array}{l}\text { Na verdade trabalho com todas as modalidades, mas } \\
\text { a mais questionada é a mediação é relacionada às } \\
\text { dúvidas dos conteúdos das disciplinas. }\end{array}$ \\
\hline
\end{tabular}

Fonte: Dados da pesquisa.

Dentre as respostas obtidas, destacam-se a T5, T6, T10, T15, T19 e T22 que justificam a realização da mediação pedagógica com maior frequência no contato com os alunos, relacionando a ação ao conteúdo trabalhado no semestre. O entendimento dos conteúdos trabalhados nas teleaulas é importante para que os alunos tenham um bom aproveitamento do semestre, portanto, cabe ao tutor a mediação entre os conceitos e as dúvidas dos alunos, atuando como facilitador do processo de ensino e aprendizagem ação que contempla também a mediação pedagógica, Masetto (2009, p.145) aborda algumas características da mediação pedagógica, que contribuem para compreensão:Dialogar permanentemente

- Trocar experiências

- Debater as dúvidas

- Questionar e problematizar

- Apresentar perguntas orientadoras

- Orientar nas carências e dificuldades

- Garantir a dinâmica do processo de aprendizagem

- Desencadear e incentivar reflexões.

A definição de Masetto (2009) corrobora com a justificativa encaminhada pelo T1, T3, T4, T8 e T14, que relatam a realização da mediação pedagógica em seu dia a dia, enquanto tutor, com mais evidência, visto as atividades que atendem no semestre, estágio, portfólio, que é uma produção textual interdisciplinar proposta pelos docentes do semestre, entre outras atividades avaliativas que compõem o semestre, deste modo, conforme bem define Masetto (2009, p.145), cabe aos tutores "orientar nas carências e dificuldades e garantir a dinâmica do processo de aprendizagem".

Entre as falas que relacionam a mediação pedagógica ao conteúdo do semestre, destaca-se a fala do T1 que diz: "Estou atualmente com o último semestre, dessa forma as interações operacionais são quase nulas. E acredito que a afetiva caminhe junto com a pedagógica". Dessa forma, foi possível observar que o T1 compreende o conceito da tríade e relaciona a mediação operacional como quase nula para alunos do último semestre, por entender que, ao longo dos semestres, o aluno talvez já tenha compreendido a operação da instituição e busque a solução de dúvidas operacionais nos setores responsáveis, ou talvez, não tenha mais problemas com a não realização de provas e postagem de trabalhos por entender o cronograma de atividades, que compõem tal operação. Além de relatar e acreditar que a mediação afetiva caminha junto à pedagógica, se voltar o olhar à proposta da tríade de mediação, é notável que ambas as mediações caminham sempre juntas e se relacionam constantemente como uma engrenagem.

O T16 completa a fala do T1 contemplando, em sua resposta, a tríade da mediação Pedagógica, Afetiva e Operacional, ao relatar:

Para os alunos do sétimo semestre, não é comum a evasão do curso, portanto, não é frequente as mediações afetivas, somente é realizada para aproximação e motivação. Nesta fase, a maioria dos alunos já tem forte conhecimento sobre questões operacionais, descartando assim, grande parte de instruções, ficando somente a mediação operacional para alguns casos específicos, como erros no sistema, dúvidas de provas de segunda chamada entre outros. Já a mediação pedagógica é intensa, as dúvidas são frequentes e em todas as disciplinas do semestre.

Já o T13 afirma como correta a realização da tríade, porém justifica a efetivação apenas da mediação pedagógica, visto o número de alunos que atende, ao relatar: Na tríade o correto seria podermos aliar todas as 3 bases, porém com a quantidade de alunos e demais atribuições usamos mais a questão pedagógica e a operacional, para termos uma mediação ao menos compensadora. Quanto ao relato do T13, é possível considerar que a compreensão da tríade pode estar evidente, todavia, ainda é preciso a compreensão da efetivação deste tripé, pois a realização deste deve ocorrer como um processo único independentemente do número de alunos atendidos ou da busca dos alunos, pois a mediação deve também partir do tutor ao apresentar perguntas orientadoras ao desencadear e incentivar reflexões (MASETTO, 2009).

Esta análise permite concluir que os tutores centralizam o conceito de mediação a uma ação ou atividade realizada e, embora tenham conhecimento da tríade de mediação, não a compreendem como um processo contínuo em todas as ações.

A relação com a afetividade no processo de mediação se mostrou evidente na fala dos tutores (Quadro 2).

Quadro 2 - Justificativa dos tutores que alegaram realizar com maior frequência a mediação Afetiva

\begin{tabular}{|l|l|}
\hline Tutor & \multicolumn{1}{|c|}{ Resposta } \\
\hline T11 & $\begin{array}{l}\text { Todas as alternativas acima fazem parte da rotina de } \\
\text { mediação. Deixei opção afetiva pois para qualquer } \\
\text { situação a afetiva é a forma como é feito a mediação } \\
\text { para qualquer situação. }\end{array}$ \\
\hline T12 & Para que o aluno sinta interesse por tal assunto. \\
\hline T17 & $\begin{array}{l}\text { Os alunos se sentem amparados, pelo envio de } \\
\text { mensagens, e respostas proativas direcionadas a eles. }\end{array}$ \\
\hline
\end{tabular}

Fonte: Dados da pesquisa. 
Entre os participantes da pesquisa, apenas três evidenciaram a mediação afetiva como a mais realizada no dia a dia de trabalho, o T11, T12 e T17.

O T11 diz que ao tratar das mediações pedagógica, afetiva e operacional, todas “fazem parte da rotina de mediação. Deixei opção afetiva, pois para qualquer situação a afetiva é a forma como é feito a mediação para qualquer situação", entende-se que por estar em constante contato com os alunos através do ambiente virtual de aprendizagem, uma relação de afetividade se estabelece entre o tutor e o aluno, o que justifica a fala do tutor, pois independente da mediação realizada, deveria haver uma afetividade no processo da troca de informação.

O T12 relaciona a afetividade ao interesse do aluno pelos assuntos que permeiam o curso em que o aluno está inserido. Acredita-se que o tutor, ao envolver o aluno afetivamente, está colaborando para o sentimento de pertencimento do aluno ao curso e ao ambiente de interação, mantém o aluno mais ativo, despertando seus interesses ao longo dos semestres.

Logo, o T17 considera a mediação afetiva "[...] pelo envio de mensagens, e respostas proativas direcionadas a eles", a fala do tutor evidencia a importância dos meios disponibilizados no ambiente virtual de aprendizagem, para a aproximação da relação entre o tutor e aluno, uma vez que por meio das ferramentas o tutor encaminha as mensagens direcionadas aos alunos. Almeida (1999, p.107) contribui, ao afirmar que:

as relações afetivas se evidenciam, pois, a transmissão do conhecimento implica, necessariamente, uma interação entre pessoas. Portanto, na relação professor-aluno, uma relação de pessoa para pessoa, o afeto está presente.

A partir da abordagem apresentada pelos tutores ao justificarem a prática da mediação afetiva e do conceito salientado por Almeida (1999), conclui-se que a afetividade deve ser parte integrante do processo de mediação de forma que os alunos se sintam amparados e tenham mais interesse nos assuntos trabalhados ao longo do semestre.

A mediação operacional também se mostrou presente na fala dos tutores ao justificarem a mediação realizada com maior frequência na relação com os alunos.

Quadro 3 - Justificativa dos tutores que alegaram realizar com maior frequência a mediação Operacional

\begin{tabular}{|l|l|}
\hline Tutor & Resposta \\
\hline T2 & $\begin{array}{l}\text { Devido a demanda e os prazos serem muito curtos, } \\
\text { infelizmente somente consigo realizar a operacional e } \\
\text { a pedagógica. }\end{array}$ \\
\hline T18 & $\begin{array}{l}\text { Os alunos enviam muitas perguntas, sobre datas de } \\
\text { prova, acesso em sistema e atividades que não foram } \\
\text { efetivadas. }\end{array}$ \\
\hline T20 & $\begin{array}{l}\text { Meu curso possui atividades extracurriculares que com } \\
\text { peso de avaliação, como por exemplo Estágio e Projeto } \\
\text { de Ensino (Que seria o TCC). }\end{array}$ \\
\hline
\end{tabular}

Fonte: Dados da pesquisa.

Entre os participantes da pesquisa, três foram os que evidenciaram a mediação operacional como a mais realizada no dia a dia de trabalho, o T2, T18 e T20.

O T2 justifica a realização da mediação operacional em função da demanda e aos prazos serem muito curtos, entretanto, mesmo selecionando apenas a mediação operacional como a mais desenvolvida em seu dia a dia de trabalho, evidencia também a pedagógica. Entende-se na fala do tutor que o cumprimento do cronograma preestabelecido pela instituição parte do escopo de trabalho do tutor como envio mensagens, correção de provas, trabalhos, interação no ambiente virtual de aprendizagem o limita para a efetivação da tríade de mediação, porém se considera-se que, como uma engrenagem, a tríade não caminha dissociada.

O T18 afirma a realização da mediação operacional vinculada às mensagens relacionadas às dúvidas referentes às datas de provas, acessos e atividades não realizadas no prazo, ações que caracterizam a mediação operacional.

Quanto ao T20, evidencia-se, por meio de seu registro, que realiza com maior frequência a mediação operacional, por atender um semestre que possui atividades extracurriculares, estágio e projeto de ensino. Entende-se, então, por se tratar da mediação operacional, que os alunos possuem dificuldades quanto às datas de realização das atividades, normas de estágio junto à divisão de convênios e estágios e lançamento de carga horária para o cumprimento das atividades complementares.

As justificativas dos tutores evidenciam que a mediação operacional compõe as atividades atribuídas ao profissional de tutoria, Silva $(2009$, p.88) salienta que o:

[...] processo de mediação, em sentido estrito, não corresponde apenas ao momento virtual em que os alunos entram em contato com o conteúdo e as atividades, interagindo com os professores, com os colegas e técnicos no AVA e (ou) por outros meios de comunicação [...].

Concorda-se com Silva (2009) de que a mediação vai além do ambiente virtual de aprendizagem e dos conhecimentos pedagógicos do tutor, diante disso conclui-se que os procedimentos administrativos compõem a mediação operacional a ser realizada, que aliada à mediação pedagógica e afetiva constitui a tríade proposta.

A tríade de mediação proposta nesta pesquisa, também se mostrou evidente nas respostas dos tutores ao justificarem a mediação realizada com maior frequência, conforme exposto no Quadro 4.

Quadro 4 - Justificativa dos tutores que alegaram realizar com maior frequência a tríade de mediação

\begin{tabular}{|l|l|}
\hline Tutor & \multicolumn{1}{|c|}{ Resposta } \\
\hline T7 & $\begin{array}{l}\text { Estou utilizando uma metodologia ativa, que incentive } \\
\text { o aluno a participar e interagir nas atividades do } \\
\text { semestre. Acolhendo, valorizando a participação, } \\
\text { sanando as dúvidas, propondo sugestões para } \\
\text { organizar os estudos e ter um melhor rendimento. } \\
\text { Fazendo o aluno se sentir importante e criando um } \\
\text { vínculo de interação. Desse modo, estimulando o } \\
\text { aluno a pensar de forma autônoma, favorecendo a } \\
\text { postura reflexiva e investigativa. }\end{array}$ \\
\hline
\end{tabular}




\begin{tabular}{|l|l|}
\hline T9 & $\begin{array}{l}\text { De um modo geral, percebo que oriento os alunos } \\
\text { com base na tríade da mediação, pois, não existe a } \\
\text { possibilidade de deixar o discente sem uma resposta, } \\
\text { ou seja, sem uma possibilidade. Então, além de acolhê- } \\
\text { lo de maneira afetiva, busco a resposta em relação } \\
\text { à sua dúvida (operacional ou pedagógica), sempre } \\
\text { utilizando empatia, cordialidade e prestatividade. }\end{array}$ \\
\hline T23 & $\begin{array}{l}\text { Na condição de Tutor, em todas as mensagens, eu } \\
\text { procurava estabelecer as três (ou pelo menos duas) } \\
\text { dimensões da mediação (Pedagógica, Afetiva e } \\
\text { Operacional), de maneira simultânea. Seja uma } \\
\text { mensagem de caráter operacional ou de cunho } \\
\text { pedagógico, o aspecto afetivo sempre deve ser } \\
\text { colocado em prática: por meio de uma saudação; } \\
\text { desejando bons estudos; chamando atenção aos } \\
\text { pontos importantes, de modo com que o aluno } \\
\text { possa se sentir único e que a mensagem possa ter } \\
\text { um caráter particular. Buscando sempre ser uma } \\
\text { resposta clara, objetiva, precisa e abrindo espaço para } \\
\text { esclarecimentos, caso o aluno tenha alguma dúvida. }\end{array}$ \\
\hline
\end{tabular}

Fonte: Dados da pesquisa.

Três foram os participantes que destacaram, em suas justificativas, a realização da tríade de mediação, abordando em sua atuação a mediação Pedagógica, Afetiva e Operacional.

Os T7, T9 e T23 mostram que a mediação Pedagógica, Afetiva e Operacional caminham juntas ao processo de mediação, como propõe a engrenagem da mediação no contato com os alunos de forma simultânea a tríade se efetiva, representa-se a fala dos tutores por meio da engrenagem e apresenta-se as palavras que evidenciam a prática da tríade.

Para cada resposta obtida foi criado um World Cloud, a fim de identificar as palavras que mais se evidenciaram nas justificativas encaminhadas que se relacionam com a tríade da mediação, a Figura 2 aborda na engrenagem da mediação as três respostas.

Figura 2 - Tríade na engrenagem da mediação

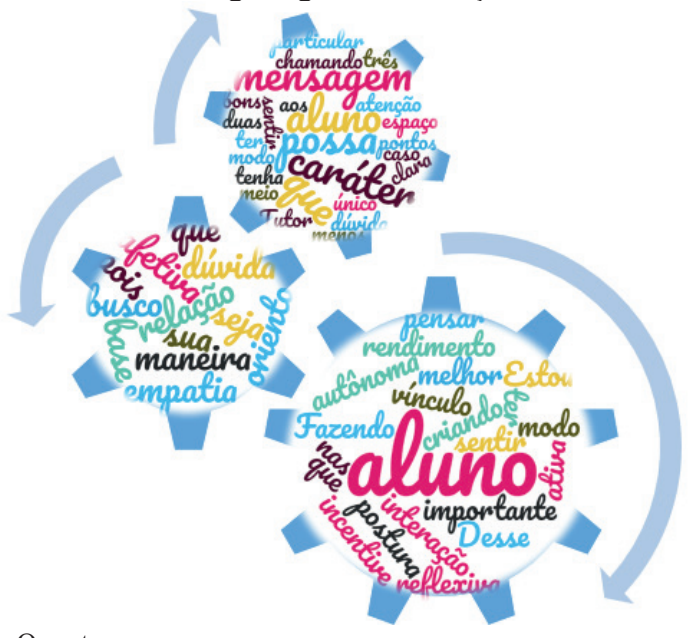

Fonte: Os autores.

É possível observar que, embora se tenham respostas diferentes quanto à realização da mediação Pedagógica, Afetiva e Operacional, os conceitos se interacionam como propõe a engrenagem. As respostas ocupam a engrenagem como um todo, independente da peça atribuída a cada uma, permitindo concluir que estes tutores aplicam o conceito da tríade da mediação em sua atuação, as peças podem se mover, porém o conceito permanecerá.

Masetto, Moran e Behrens (2000, p.145-146) corroboram com tal compreensão ao definirem a mediação como:

[...] dialogar permanentemente com o que acontece no momento; trocar experiências; debater dúvidas, questões ou problemas; apresentar perguntas orientadoras; orientar nas carências e dificuldades técnicas ou de conhecimento quando o aprendiz não consegue encaminhá-las sozinho; garantir a dinâmica dos processos de aprendizagem; propor situaçõesproblema e desafios; desencadear e incentivar reflexões; criar intercâmbio entre a aprendizagem e a sociedade onde nos encontramos, nos mais diferentes aspectos; colaborar para estabelecer conexões entre o conhecimento adquirido e novos conceitos; fazer a ponte entre outras situações análogas; colocar o aprendiz frente a frente com questões éticas, sociais, profissionais por vezes conflitivas; colaborar para desenvolver crítica com relação à quantidade e à validade das informações obtidas; cooperar para que o aprendiz use e comande por elas ou por quem as tenha programado; colaborar para que se aprenda a comunicar conhecimentos, seja por meios convencionais, seja por meio de novas tecnologias.

Desta forma, observa-se que características comuns à tríade de mediação, convergem com o exposto pelos tutores ao relatarem a mediação realizada no ambiente virtual de aprendizagem, elementos que convergem com a abordagem de Masetto, Moran e Behrens (2000) quanto ao conceito de mediação, o que permite concluir que os tutores, que afirmam realizar a mediação Pedagógica, Afetiva e Operacional, agrupam em seu dia a dia no processo de mediação os diferentes elementos que caracterizam a tríade, mantendo a relação constante entre as "peças", que compõem a engrenagem.

\section{Conclusão}

As análises evidenciaram que os tutores compreendiam a importância da mediação em suas ações junto aos alunos e que os programas de formação continuada oferecidos pela instituição contribuem diretamente para o enriquecimento profissional de seus tutores, uma vez que tal compreensão se faz importante para a realização da mediação e, consequentemente, para a efetivação da tríade Pedagógica, Afetiva e Operacional que compõe o tripé proposto pela instituição.

Verifica-se ainda que muitos tutores centralizam a mediação realizada apenas na pedagógica, afetiva ou operacional, o que permite concluir que, embora tenham conhecimento da tríade de mediação, não a compreendem como um processo contínuo em todas as ações.

\section{Referências}

ALMEIDA, A.R.S. A emoção na sala de aula. Campinas: Papirus, 1999.

BRASIL. Secretaria de Educação a Distância. Referenciais de qualidade para educação superior a distância. Brasília: MEC, 2007.

MASETTO, M.T.; MORAN, J.M.; BEHRENS, M.A. Novas tecnologias e mediação pedagógica. Campinas: Papirus, 2000.

MASETTO, M.T. Mediação pedagógica e o uso da tecnologia. 
In: MORAN, J.M.; MASETTO M.T.; BEHRENS, M.A. Novas tecnologias e mediação pedagógica. São Paulo: Papirus, 2009. p.133-173.

MORAN, J.M. Novas tecnologias e mediação pedagógica. São Paulo: Papirus, 2000.

MOORE, M.G.; KEARSLEY, G. Educação a distância: uma visão integrada. São Paulo: Cengage Learnin, 2011.

MOORE, M.G.; KEARSLEY, G. Educação a distância: sistemas de aprendizagem on-line. São Paulo: Cengage Learning, 2013.

MINAYO, M.C.S. (Org.). Pesquisa social: teoria, método e criatividade. Petrópolis: Vozes, 1994.

BRASIL. Ministério da Educação. Secretária de Educação a Distância. Referencial de qualidade para os cursos a Distância. Brasília. MEC, 2007.

PRADO, M.E.B.B. Educação a distância e formação do professor: redimensionando concepções de aprendizagem. 2003. Tese (Doutorado em Educação) - Pontifícia Universidade Católica, São Paulo, 2003.

SILVA, S.F.K. A ação docente na EaD: a mediação do tutor entre o discurso e a prática. 2009. Tese (Doutorado em Educação) Universidade Metodista de São Paulo, 2009. 